guerilla who survives, did not venture into exposed regions where he was not comfortable. He stayed with small science, with classical atoms and with linear optical phenomena and their mathematics, as gradually heavy theoretical and physical apparatus became predominant. Nevertheless, when he was Cavendish Professor he encouraged radio astronomy and did not hinder nuclear physics.

Bragg was indeed fortunate in that his abilities matched the challenges and the times, however, it was not accident but skill that was necessary in assessing the abilities and the challenges and pitting one against the other. We see him, in about 1956, like Napoleon in his tent, privately estimating the coordinates of the heavy atoms in myoglobin using his own methods (where J. Kendrew was using the earliest available computer) and concluding that victory was then certain in the campaign to find the positions of the atoms in the first protein.

A number of Bragg's most characteristic papers (some rather difficult to find elsewhere) are reprinted in Selections and we may enjoy reading his advice on how to give a lecture about science (from Marine Technology, 1967). From this we realize that the apparently easy performance of lectures was the result of much thought on presentation and style. Apparent simplicity is not just simple, but is the result of the paring away of inessentials and looking at the relationships between a few key components. Nevertheless, as in a computer program, these few components may form one level in a hierarchic structure of considerable overall complexity.

We may ask today: are there still big problems in science where simplicity will get you the answer? Bragg's strategy was "Do not follow the fashion and do not hesitate to try an experiment which the theorists hold to be stupid."

Probably there are such problems, because, for example, computing and mathematics have been simplified by computer packages and there are huge databases which may be reckoned as simple. But they are harder to find and we need insight to see them. Somehow this is what Bragg had in abundance and what, in his lectures, he managed to communicate to others. As an undergraduate I heard him explain the birefringence of calcite with the excitement of someone who had realized only yesterday, and not a decade before, how the carbonate group worked in this respect. It is worthwhile studying how all this came about. Bragg was indeed fortunate that one paradigm carried him right through for 50 years, from the discovery of X-ray diffraction to the solving of the first protein structures. But he also had the vision to see the way ahead at each step, avoiding intractable complexity.

Alan Mackay is in the Department of Crystallography, Birkbeck College, University of Lon don, Malet Street, London WC1E 7HX, UK.

\section{Big science biology}

\section{Kevin Davies}

Mapping the Code. By Joel Davis. Wiley: 1991. Pp.294. £14.95, $\$ 21.95$.

Around the time of the Human Genome II conference in San Diego last year, the science correspondent for one of the major US television networks introduced a short item for the daily breakfast-TV programme on the goals of the Human Genome Project. It started promisingly enough - the familiar scene of a modern laboratory setting, people in white coats looking quizzically at autoradiographs, steady hands loading gels with purple markers; in short a typical day in the laboratory. Some carefully selected sound bites revealed that humans have about 100,000 genes, and that the aim of the project is to map them and eventually elucidate their function, with unimaginable rewards in the battle against diseases such as Alzheimer's and cancer.

But as the reporter handed back to Joe Garagiola, the long-retired ex-baseball star, in the New York studio the debate floundered as the camera caught the studio lights shining off his head; it seemed that what $\mathrm{Mr}$ Garagiola was more interested in was whether there was a gene for baldness, and when the scientists might find it. Joe and the reporter laughed for a few moments over the satellite link-up before the station abruptly cut to a commercial. As in-depth documentaries go, it may not have been much, but for the American public at least, it was a start.

In more academic circles, of course, arguments about the scientific merits and funding of the genome project have raged for years. The original notion of sequencing megabases of 'junk' DNA has been scotched, as most scientists seem to agree that mapping the human genome first and then sequencing the interesting regions, is the most sensible way to sell the project and its vast cost (by biology standards at least) to the politicians, researchers, and the public at large.

Given the enormous scale and estimated cost of the project, it is no surprise that a number of books professing to reveal the true workings of the project have appeared - at least three in the last six months. The dust jacket of Joel Davis's Mapping the Code (which contains by far the most colourful prose in the book) asserts that "Davis manages the impossible: he mixes hard science with human drama and history," but his analysis of the science is far poorer than managed in Genome, by Jerry Bishop and Michael Waldholz (Simon and Schuster, 1990: for review see Nature 348, 205; 1990), and in contrast to Lois Wingerson's readable and entertaining Mapping Our Genes (Dalton, 1990), virtually all signs of human life are sadly lacking. The only remotely revealing insight that Davis uncovers is Paul Berg's knack of winning several cases of wine from distinguished colleagues on bets ranging from the extent of alternative splicing to the significance of 'junk' DNA.

Mapping the Code tackles the evolution of the genome project in greater detail than its predecessors, but debates such as which agency should coordinate the project and who should lead it simply do not make for enthralling reading. Much of the early portion of the book, in which Davis sketches the molecular genetic methods involved, is culled from congressional reports. The middle section details the meetings in the mid-1980s that led to the proposal to map the genome, drawing on numerous articles published in Science magazine at the time. But in Davis' hands, any sense of excitement or controversy is buried by his zeal in highlighting every meeting that took place, together with long (and tedious) lists of the participants, not to mention their affiliations. When he does become animated, it is over wholly unimportant subjects, such as whether the genome project should be classified as 'small Big Science' or 'big Small Science'.

The last third of the book is an improvement, as -Davis touches on some of the important questions arising from the project itself: who owns the genome and its constituent chromosomes? How and when will we develop the supercomputers needed to analyse the bounty of information that the project will produce? And what are the potential uses and misuses of our own individual genetic map, assuming (as Davis does) that in 50 years or so we might be carrying around floppy disks with this very information?

For the most part, however, Davis shies away from a discussion of how the project should be structured. Is a 'top-down' format the most effective way of reaching our goal of a complete genetic map, or is it best to encourage the innovative investigators, as some such as Don Brown continue to argue? In the year or so since Mapping the Codewas finished, genes reponsible for some forms of retinitis pigmentosa, Alzheimer's disease and colon cancer have been identified, to name but a few. It is especially ironic that a fundamental understanding of Alzheimer's disease has long been promoted (especially by Jim Watson) as one of the reasons to map and sequence chromosome 21 , and yet one mutation already appears to have been identified, and other gene loci are being located.

No matter how the map eventually comes about, the important task is that the genome project should help in the identification of genes that either cause or predispose one towards cancer, mental illness, and of extreme importance to some - even baldness.

Kevin Davies is an Assistant Editor of Nature. 